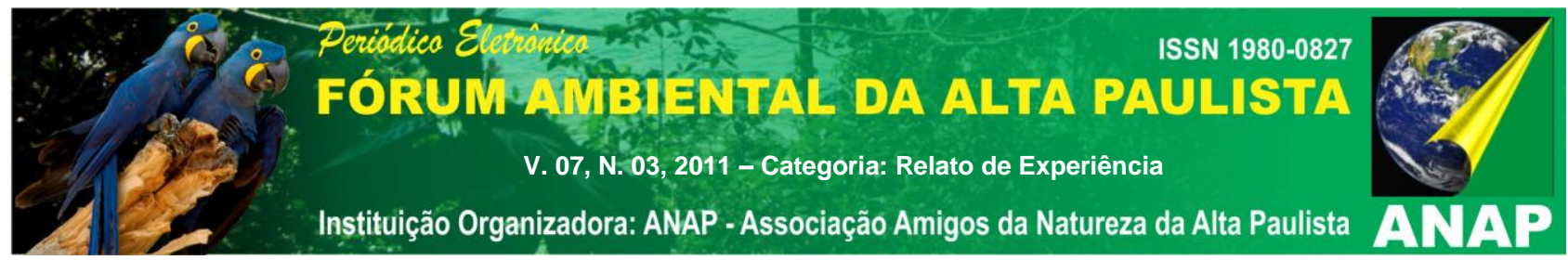

\title{
MONITORAMENTO DE REFLORESTAMENTOS EM ÁREAS DE RESTAURAÇÃO DE MATA ATLÂNTICA ÀS MARGENS DOS RESERVATÓRIOS DA CESP
}

Nome do Autor Principal

\section{André Ricardo Brasilino Rocha}

Nomes dos Co-autores

Maria José Neto; Celso Machado; Washington Luiz de Azevedo Geres.

RESUMO: O Programa de Manejo de Flora e Reflorestamento da CESP tem entre seus objetivos a mitigação do processo de fragmentação e degradação de matas nativas, que é um dos principais riscos à biodiversidade. Na recomposição de matas ciliares a empresa utiliza procedimentos que visam à auto-renovação e à sustentabilidade de seus reflorestamentos, começando pela qualidade genética e fisiológica das sementes coletadas, produção de alta diversidade de mudas de espécies autóctones e plantio florestal em cultivo mínimo. Para maior eficácia dos recursos empregados e aferição de que as ações executadas estão de fato promovendo a sua restauração e perpetuação no tempo, é desenvolvido um plano de monitoramento dos reflorestamentos, onde são avaliados os projetos de reflorestamento exigidos no licenciamento ambiental da UHE Engenheiro Sérgio Motta (Porto Primavera). Este trabalho possibilita direcionar as atividades de manutenção de acordo com as condições de cada lote avaliado, apontar problemas como invasão de gado e roubo de cercas a serem combatidos e indicar locais que já apresentam o início de uma estruturação ecológica, com formação também de estratos não arbóreos e recrutamento de inúmeras formas de vida.

Palavras-chave: Monitoramento. Reflorestamento. Restauração. 


\section{INTRODUÇÃO}

A urbanização, agricultura, industrialização e outras atividades antrópicas vêm impactando os ecossistemas naturais, levando a um aumento de áreas degradadas e de paisagens fragmentadas, com baixa conectividade entre os fragmentos florestais remanescentes, o que reduz a biodiversidade e aumenta o risco de extinções locais de espécies (KAGEYAMA \& GANDARA, 2005). Somente entre 2002 e 2008 a Mata Atlântica teve 2,7 mil $\mathrm{Km}^{2}$ de sua área desmatada, com uma taxa média de $457 \mathrm{Km}^{2}$ por ano (IBAMA, 2010).

Ao longo do tempo, as florestas paulistas foram progressivamente transformadas em pequenos remanescentes, isolados e inseridos em paisagens alteradas pelo homem. Esse processo, conhecido com fragmentação de habitats (latu sensu), é considerado atualmente uma das maiores ameaças à biodiversidade global (PIRES et al., 2006).

A restauração de ecossistemas naturais degradados tem um papel fundamental para reduzir a extensão desses problemas, especialmente em situações mais sensíveis como áreas ciliares, consideradas de preservação permanente. As técnicas empregadas pela restauração ecológica têm avançado nos últimos anos, devido ao acúmulo de conhecimentos nas áreas de ecologia florestal (regeneração, sucessão florestal e interações ecológicas), na sistemática e na tecnologia de produção de sementes e mudas (KAGEYAMA \& GANDARA, 2005).

Diversas instituições públicas e não governamentais vem atuando na restauração florestal, mas a CESP - Companhia Energética de São Paulo, destaca-se pelo seu pioneirismo nessa atividade e pela grande escala de atuação, com vasta aplicação desses conhecimentos em plantios realizados há mais de 30 anos nas áreas de influência dos reservatórios de suas usinas hidrelétricas (FERRETTI, 2001).

A busca contínua pelo aprimoramento das ações ambientais levou a CESP a firmar convênios com o Instituto de Pesquisas e Estudos Florestais (IPEF), vinculado à Escola Superior de Agricultura Luiz de Queiroz (ESALQ), da USP - Universidade de São Paulo. Desses convênios, vigentes entre 1988 e 2001, muitos avanços foram obtidos, como a redução dos custos de produção de mudas e do plantio, o que favoreceu 0 desenvolvimento conceitual e tecnológico da principal ferramenta de restauração 


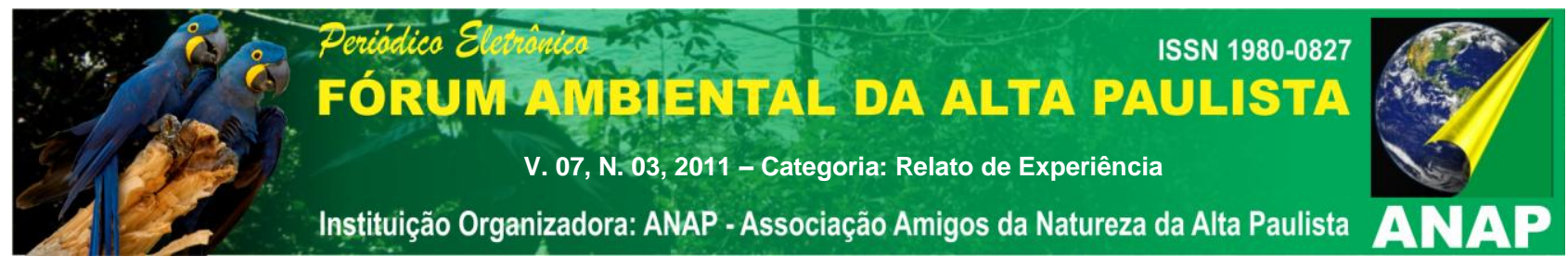

ecológica para a CESP, que é o reflorestamento com espécies nativas. Segundo Kageyama (2003), essa cooperação foi "um dos acontecimentos fundamentais para o avanço científico e tecnológico na área de restauração de áreas degradadas no Brasil”.

O monitoramento das áreas reflorestadas é de extrema importância para a confirmação que as ações de restauração implantadas estão de fato promovendo a sua restauração ecológica e perenização. Deve ser considerada também a quantificação do incremento dos serviços ambientais (regularização hidrológica, proteção de solos, incremento da biodiversidade regional, fixação de carbono etc.) ao longo do processo de restauração florestal (BELLOTTO et al., 2009). Para a avaliação e monitoramento de projetos de restauração é importante considerar que para as diferentes etapas do processo de restauração são necessárias diferentes variáveis de avaliação.

Para tanto, é importante empregar indicadores que avaliem não só a ocupação gradual e crescente da área por indivíduos de espécies nativas, mas também a distribuição dessas espécies em grupos funcionais.

Os indicadores devem medir a cobertura da área e a alteração da fisionomia e da diversidade local promovida por essa ocupação (RODRIGUES et al., 2004), já que o conhecimento da estrutura e composição dos estratos inferiores de florestas pode fornecer dados para inferir sobre as condições ambientais e o estado de conservação de comunidades florestais (RICHARDS, 1952), pois espécies herbáceas e arbustivas de subbosque são sensíveis às mudanças micro-climáticas, edáficas e ecológicas intrínsecas ao processo de sucessão ecológica (GIVNISH, 1986; VEBLEN et al., 1979; POULSEN, 1996; TURNER et al., 1996).

\section{OBJETIVO GERAL}

Aferir a efetividade da restauração ecológica de áreas degradadas reflorestadas com espécies nativas executada pela CESP.

\section{OBJETIVOS ESPECÍFICOS}




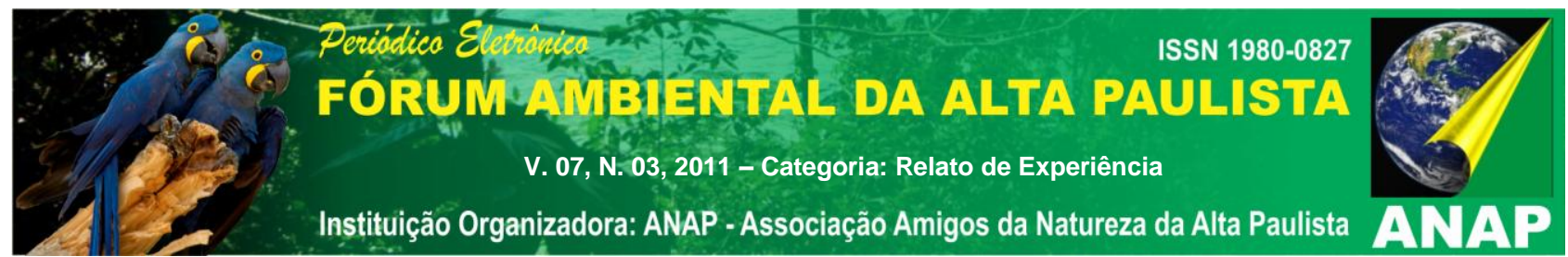

i) Avaliar o crescimento e sustentabilidade dos maciços florestais já implantados pela CESP através de vistorias nas áreas implantadas.

ii) Direcionar as atividades de manutenção de acordo com as necessidades apontadas em cada lote monitorado.

iii) Averiguar a ocorrência de invasões nas áreas reflorestadas para executar as devidas providências.

v) Levantar as principais sinúsias herbáceas, epifíticas e arbustivas regenerantes nas áreas.

\section{METODOLOGIA}

As áreas monitoradas situam-se na Bacia Hidrográfica do Alto Paraná, das coordenadas 22 K 0297799, 75277428 a 22K 0393091, 7597647 UTM, Datum SAD 69, às margens do reservatório da UHE Engenheiro Sérgio Motta, em Anaurilândia, MS, totalizando 350,00 hectares.

Os indicadores de avaliação e monitoramento foram agrupados de maneira a facilitar o entendimento dos principais aspectos referentes ao processo de restauração (MELO, 2010). Para a obtenção dos dados em campo foram realizadas atividades simples, tais como avaliações visuais de infestação de ervas invasoras e formigas, estado nutricional, etc. A estrutura da cobertura vegetal, a presença de regenerantes e o desenvolvimento geral das plantas foram escolhidos como indicadores da restauração estrutural da florestal, já que a quantidade, qualidade e distribuição da luz condicionam os microhabitats internos do reflorestamento e interferem no crescimento e sobrevivência das plântulas, determinando mudanças na composição da comunidade. Além da importância para restauração da estrutura e processos originais da floresta, a rápida promoção da cobertura é importante para o controle de plantas invasoras e a interceptação da água das chuvas nas copas possibilita a estabilização do solo.

Após definidos os indicadores, montou-se uma planilha de monitoramento, com os seguintes campos para preenchimento: cobertura vegetal; nível de infestação por gramíneas invasoras; grau de infestação por formigas cortadeiras; presença de frutos; 


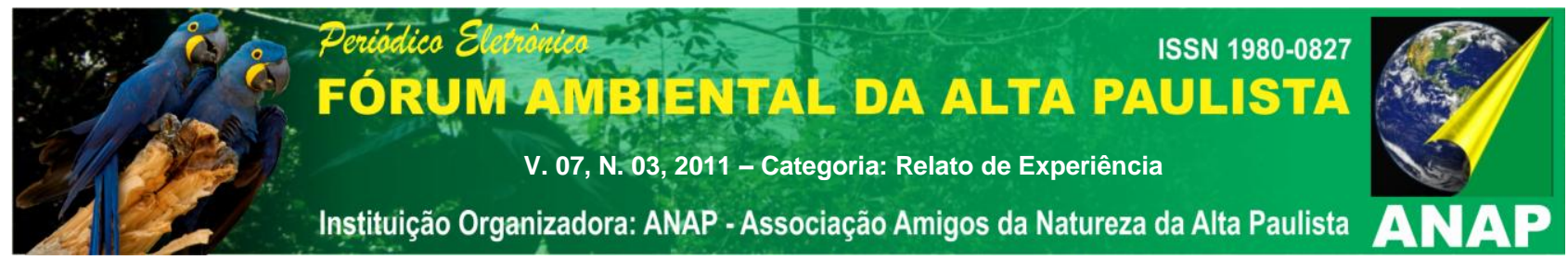

estratificação do dossel; desenvolvimento e estado nutricional das plantas; biodiversidade vegetal; taxa de sobrevivência; invasão por animais domésticos; solapamentos e outros processos erosivos; estado de conservação das cercas.

As áreas avaliadas são identificadas por lotes, relacionadas às propriedades rurais onde estão situadas, com registro de coordenadas UTM e outras referências de localização pertinentes. As avaliações são feitas no campo, com acesso via estrada ou rio, onde os técnicos caminham dentro de cada área e registram inclusive por meio fotográfico.

O levantamento das sinúsias não arbóreas foi realizado separadamente, no mês de fevereiro de 2011, nos lotes que foram definidos como promissores pelo trabalho de monitoramento.

\section{RESULTADOS}

As variáveis avaliadas, com seus respectivos valores, estão relacionados na Tabela 1.

Tabela 1. Indicadores do monitoramento

\begin{tabular}{lll}
\hline Descrição & Sim & Não \\
\hline É necessário conserto da cerca & $26 \%$ & $74 \%$ \\
Constatada a presença de animais/gado & $39 \%$ & $61 \%$ \\
É necessário controle de invasoras & $39 \%$ & $61 \%$ \\
É necessário replantio de mudas & $15 \%$ & $85 \%$ \\
É necessária uma adubação química & $19 \%$ & $81 \%$ \\
É necessário controle de formigas & $19 \%$ & $81 \%$ \\
É necessário controle de cupins & $8 \%$ & $92 \%$ \\
Presença de processos erosivos & $22 \%$ & $78 \%$ \\
Lotes afetados por solapamento & $15 \%$ & $85 \%$ \\
\hline
\end{tabular}

A Figura 2 apresenta gráficos de distribuição dos lotes avaliados dentro dos indicadores silviculturais pré-definidos. 

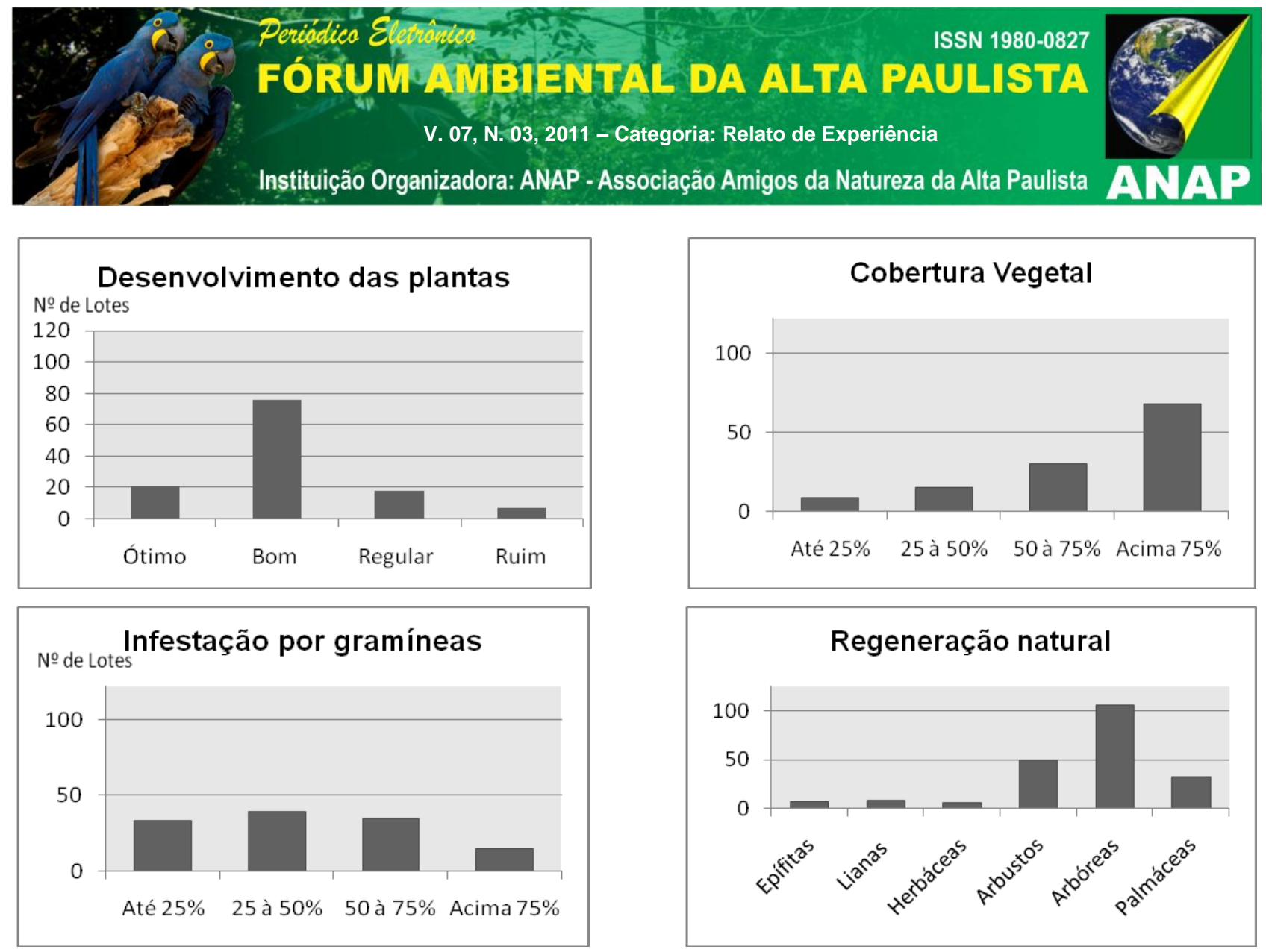

Figura 2. Classificação dos lotes quanto aos indicadores silviculturais.

Quanto ao levantamento das sinúsias não arbóreas, obteve-se a identificação das seguintes espécies, baseado em Neto et al. (2010): Celtis pubescens Planch.; Chaptalia nutans Hemsl.; Bidens gardneri Baker.; Schubertia grandiflora Mart\&Zucc.; Doryopteris palmata kileen.; Oeceoclades maculata (Lindl.) Lindl.; Ipomoea nil Roth.; Lantana trifolia L.; Maranta arundinacea L.; Orthopappus angustifolius (Sw.) Gleason; Oxypetalum banksii Roem. \& Schult.; Passiflora sp.; Polygonum sp.; Prestonia tomentosa R.Br.; Randia armata (Sw.) DC.; Senna sp.; Smilax cissoides Mart.; Solanum paniculatum L.; Tillandsia gardneri Lindl.; Walteria indica L.

\section{CONSIDERAÇÕES FINAIS}

O diagnóstico realizado nos reflorestamentos permitiu identificar e planejar as intervenções necessárias e otimizar os recursos aplicados. As áreas afetadas por erosão aguardam a definição de procedimentos técnicos que vêm sendo gerados por um projeto em andamento sobre proteção de encostas em reservatórios, para futuras intervenções. 


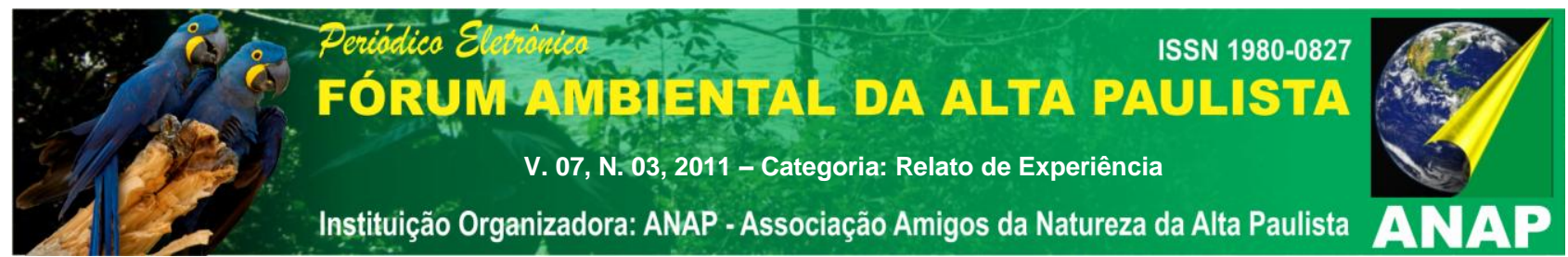

A formação de novos estratos demonstra a evolução do sistema e indica que o sítio modificado pelo plantio misto de plantas arbóreas está proporcionando condições para o surgimento e crescimento de outras formas de vida, as quais podem vir de bancos de sementes que ali existam ou através do recrutamento de fragmentos florestais próximos. Algumas dessas novas espécies requerem condições específicas de ambiente, próprias de matas preservadas, sendo um importante indicador de sucesso no processo de restauração.

É importante que trabalhos dessa natureza continuem sendo realizados nas áreas reflorestadas e possam estender-se a levantamento de lianas e outras formas de vida, como fungos saprófitos que já foram registrados nessas áreas, por exemplo.

\section{REFERÊNCIAS}

BELLOTO, A. et al. Monitoramento das áreas restauradas como ferramenta para avaliação da efetividade das ações de restauração e para redefinição metodológica. In: RODRIGUES, R. R., BRANCALION, P. H. S., ISERNHAGEN, I. Pacto pela restauração da mata atlântica: referencial dos conceitos e ações de restauração florestal. Universidade de São Paulo: LERF/ESALQ; Instituto BioAtlântica. Piracicaba, 2009. p. 132-150.

FERRETTI, A. R.; KAGEYAMA, P. Y.; QUEDA, O. O programa de fomento florestal do viveiro da CESP de Porto Primavera e a situação do fomento florestal com espécies nativas no Estado de São Paulo. Circular Técnica IPEF, n. 193. Piracicaba, 2001.

GIVNISH, T.J. Biomechanical constraints on crown geometry in forest herbs. In On the economy of plant form and function (T.J. Givnish, ed.). Cambridge University Press, New York, 1986. p. 525-583.

IBAMA. Relatório do Desmatamento no Bioma Mata Atlântica. Disponível em: <http://www. siscom.ibama.gov.br>. Acesso em: 27. jul. 2011.

KAGEYAMA, P.Y. Introdução. In: KAGEYAMA, P.Y. et al. (Org.) Restauração ecológica de ecossistemas naturais. Botucatu: FEPAF, 2003. p. 7-8. 


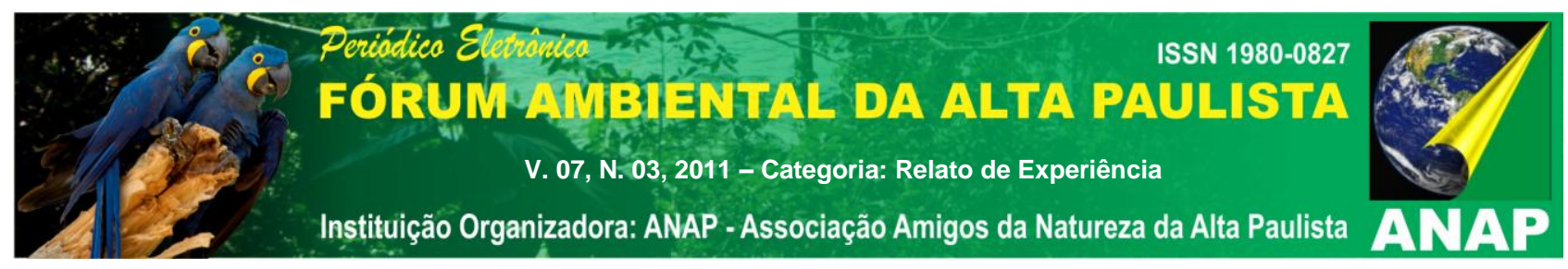

KAGEYAMA, P. Y.; GANDARA, F. B. Resultados do programa de restauração com espécies arbóreas nativas do convênio ESALQ/USP e CESP. In: GALVÃO, A. P.; PORFÍRIO DA SILVA, V. (Ed.). Restauração Florestal: fundamentos e estudo de casos. Colombo: Embrapa Florestas, 2005. 139 p.

MELO, A.C.G., Guia para Monitoramento de Reflorestamentos para Restauração. Circular Técnica 1. Secretaria do Meio Ambiente, Departamento de Proteção da Biodiversidade. São Paulo - SP. SMA. UCPRMC, 2010.

NETO, M.J.; OTSUBO, H.B.C.; CASSIOLATO, A.M.R. Plantas Ruderais. Campo Grande, MS: Ed. UFMS, 2010, 363 p.

PIRES, A.S. et al. Vivendo em um Mundo em Pedaços: Efeitos da Fragmentação Florestal sobre Comunidades e Populações Animais. In: ROCHA, C. F. D., BERGALLO, H. G., SLUYS, M. V., ALVES, M. A. S. (Ed.) Biologia da Conservação: Essências. São Carlos: RiMa, 2006. 582 p.

RICHARDS, P.W. The tropical rain forest: an ecological study. Cambridge University Press, Cambridge, 1996.

RODRIGUES, R.R.; GANDOLFI, S. Conceitos, tendências e ações para recuperação de florestas ciliares. In: RODRIGUES, R.R.; LEITÃO-FILHO, H. de F. (Eds.) Matas ciliares: conservação e recuperação, São Paulo: EDUSP, 2004. p. 235-247.

VEBLEN, T.T., VEBLEN, A.T. \& SCHLEGEL, F.M. Understorey patterns in mixed evergreen-deciduous Nothofagus forests in Chile. 1979. Journal of Ecology 67:809-823. 